\title{
Review of safety and mobility issues among older pedestrians
}

\author{
Isabelle Tournier $^{\mathrm{a}, \mathrm{b}, *}$, Aurélie Dommes $^{\mathrm{b}}$, Viola Cavallo ${ }^{\mathrm{b}}$ \\ a INSIDE, University of Luxembourg, 11 porte des sciences, L-4366 Esch-sur-Alzette, Luxembourg \\ ${ }^{\mathrm{b}}$ LEPSIS, IFSTTAR, 25 allée des Marronniers, F-78000 Versailles, France
}

\section{A R T I C L E I N F O}

\section{Article history:}

Received 14 September 2015

Received in revised form 9 February 2016

Accepted 29 February 2016

\section{Keywords:}

Pedestrians

Aging

Safety

Mobility

Functional changes

Recommendations

\begin{abstract}
A B S T R A C T
Although old people make up an extremely vulnerable road-user group, older pedestrians' difficulties have been studied less extensively than those of older drivers, and more knowledge of this issue is still required. The present paper reviews current knowledge of older-adult problems with the main components of pedestrian activity, i.e., walking and obstacle negotiation, wayfinding, and road crossing. Compared to younger ones, old pedestrians exhibit declining walking skills, with a walking speed decrease, less stable balance, less efficient wayfinding strategies, and a greater number of unsafe road crossing behaviors. These difficulties are linked to age-related changes in sensorial, cognitive, physical, and self-perception abilities. It is now known that visual impairment, physical frailty, and attention deficits have a major negative impact on older pedestrians' safety and mobility, whereas the roles of self-evaluation and self-regulation are still poorly understood. All these elements must be taken into consideration, not only in developing effective safety interventions targeting older pedestrians, but also in designing roads and cars. Recent initiatives are presented here and some recommendations are proposed. (c) 2016 Elsevier Ltd. All rights reserved.
\end{abstract}

\section{Introduction}

A common desire among older adults is to stay where they are as they age, while remaining mobile in their familiar environment (Lord and Luxembourg, 2006). The ability to stay connected to community services and to maintain social interactions is considered today to be crucial to well-being and successful aging (for a review, see Yen and Anderson, 2012). Beyond the need for mobility, walking is known to be the most common physical activity of older adults (McPhillips et al., 1989) and to have positive effects on health, cognition, and well-being (see e.g., Fox et al., 2007; for a review, see Kramer and Erickson, 2007). However, walking may be dangerous because it exposes the walker to accident risks and falling.

Within the last few decades, research has mostly focused on the safety of older drivers. The study of older pedestrians is more recent and more limited, even though a large portion of pedestrian accidents involve an older adult. For example, in Italy, Greece and France, more than half of all pedestrians killed on the road are over 65 years of age, whereas this age group represents a much smaller part (17-20\%) of the population (ONISR,

\footnotetext{
* Corresponding author at: INSIDE, University of Luxembourg, Maison des Sciences Humaines, 11 porte des sciences, L-4366 Esch-sur-Alzette, Luxembourg.

E-mail address: isabelle.tournier@uni.lu (I. Tournier).
}

2006; SafetyNet, 2009). The same pattern of over-implication of older adults in pedestrian casualties and injuries has also been observed in non-European countries such as New Zealand (Keall, 1995).

Being hit while crossing a street is not the only safety risk encountered by pedestrians: the risk of falls also increases dramatically with aging. About one third of adults age 65 or older have experienced a fall within the past year (for a review, see Lord et al., 2001). More than half of all falls in independent older community-dwelling people occur outside the home (Fothergill et al., 1995; Lord et al., 2001). Although the data are scarce, a study conducted on the US population reported that $77.5 \%$ of pedestrian's nonfatal injuries were linked to a fall; accidents while crossing the street (15\%) and overexertion (5.8\%) were the other main causes (Naumann et al., 2011; see also Abou-Raya and ElMeguid, 2009).

The aim of the present paper was to comprehensively portray older pedestrians' safety difficulties in carrying out three main tasks involved in travel on foot, i.e. walking and obstacle negotiation, navigation, and street crossing. To provide a more general understanding of these difficulties, we also report the underlying functional changes that occur with aging (sensorial, cognitive, and physical) and their consequences on pedestrian safety and mobility. Identifying risky situations and their main causes is a preliminary step toward developing efficient actions aiming at improving the safety and mobility of older pedestri- 
ans. Some of these programs are presented at the end of the paper.

\section{Walking and obstacle negotiation}

Directly linked to the risk of falling, walking and obstacle negotiation are two major components of pedestrian mobility that change during aging.

\subsection{Walking and gait characteristics}

A decrease in walking speed during aging is a typical observation, and older women are generally reported to walk more slowly than older men (see e.g., Asher et al., 2012; Knoblauch et al., 1996; Romero-Ortuno, 2010; Romero-Ortuno et al., 2010). Similarly, the acceleration capacity also reduces with aging (Buckley et al., 2009). When required to change from walking at one's preferred speed to walking quickly, the elderly fail to achieve the same increases in speed and stride length as those achieved by young adults (Shkuratova et al., 2004).

Several parameters other than walking speed also change with advancing age, where we find shorter stride lengths, greater standing widths and more time spent on the double support phase (i.e., both feet on the ground), a bent posture, and a less vigorous force development at push off time (Salzman, 2010; Winter et al., 1990). These changes are commonly noted as early as age 65 , but become more marked and limit mobility to a greater extent after the age of 85. Cautious walking and standing behaviors may reflect adaptation to age-related changes affecting the sensory, motor, and cognitive systems (for reviews, see e.g., Al-Yahya et al., 2011; Salzman, 2010), and may also mainly express fear of falling (see e.g. Espy et al., 2010). Although such gait disturbances are frequent in older persons and are often an early manifestation of a subclinical disease, about $20 \%$ of older adults are found to retain normal gait patterns into very old age (i.e., over 85; see the review by Salzman, 2010).

Among the various phases involved in walking, gait initiation and cessation are the most risky periods due to the complex postural adjustments they require (Uemura et al., 2012). Both walking initiation and cessation slow down with aging (e.g., Cao et al., 1998; Halliday et al., 1998; Winter et al., 1990). This slowing seems to be partly explained by the more cautious strategy of older adults, who need to be careful of their gait (Muir et al., 2014; Tirosh and Sparrow, 2004). It seems that older adults prefer stability over speed (Buckley et al., 2009) and placing priority on this sensorimotor performance may even be detrimental to other kinds of performance (see e.g., Shumway-Cook et al., 1997). With aging, gait cannot be conceived of as the outcome of a series of identical, automatic steps. Instead, gait performance becomes a complex task that places demands on the sensory and cognitive systems (Sheridan and Hausdorff, 2007). Given their fear of falling (e.g., Scheffer et al., 2008) and their need to keep their balance when walking (Woollacott and Tang, 1997), older pedestrians seem to allocate more attention to watching their steps as they cross, causing them to at least partly disregard approaching traffic (Avineri et al., 2012). The presence of curbs at the beginning and end of a street-crossing task may add supplementary cognitive and motor demands that very few studies have examined in a detailed manner (see e.g., Naveteur et al., 2013).

The use of canes or a walker is an effective adaptive means of reducing the risk of falling (for a review, see Alexander, 1996). Logically, older pedestrians using canes or walkers walk more slowly than older pedestrians who are not using such devices, and again, in the case of the use of canes, older women appear to walk more slowly than older men (Thompson and Medley, 1995), although this gender effect is not always observed (Arango and Montufar, 2008).

\subsection{Obstacle negotiation}

Walking is also challenged by the presence of obstacles such as uneven surfaces (e.g., cobblestone, stones, cracks), but also obstacles to be avoided (e.g., other pedestrians, benches) or to step over. Tripping over an obstacle is actually one of the most common causes of falls among older adults (Blake et al., 1988; Campbell et al., 1989). Avoiding an obstacle is risky too: having to change one's direction while walking is associated with more gait variability and a risk of falling among older people (Meinhart-Shibata et al., 2005).

Several adaptive strategies are used by older pedestrians who are confronted with obstacles. Older adults tend to adopt a slower, more conservative obstacle-negotiation strategy that gives them more time to adjust their foot trajectory (for a review, see Galna et al., 2009). In the presence of uneven surfaces, for example, they have been shown to decrease their walking speed and their step length more than younger adults do (Marigold and Patla, 2008). Moreover, older adults have been found to spend more time looking at the ground during obstacle avoidance, whereas younger adults spend more time gazing straight ahead (Paquette and Vallis, 2010). Finally, the maintenance of a large personal space between themselves and other pedestrians is another strategy used by older adults to reduce the risk of bumping into someone and falling (Gérin-Lajoie et al., 2006).

One of the main obstacle-negotiation situations encountered by city-dwelling pedestrians is handling sidewalks. Despite efforts from local authorities to provide lowered sidewalks at pedestrian crossings, moving from a sidewalk into the street is frequently associated with gutters and level or surface changes that challenge older pedestrians. While specific studies on sidewalk negotiation during street crossing by older pedestrians are scarce, some insights have been provided by studies about climbing stairs and stepping over obstacles with aging. Indeed, going up and down stairs is rated by older adults to be among the most difficult tasks in their daily life (Williamson and Fried, 1996). Falls are three times more frequent during descent than ascent (Svanström, 1974; Tinetti et al., 1988), which seems often to be explained by a decline in the ability to regulate body sway during the stair-to-floor transition when descending (Lee and Chou, 2007). In response to these changes, older adults adopt cautionary behaviors in stair cases, such as lowering their speed, watching their feet while walking, and using the handrails (Hamel and Cavanagh, 2004).

\section{Wayfinding}

Wayfinding is another important pedestrian activity. It can be divided into preparing for the journey (i.e., planning) and navigating while walking (i.e., moving and orientation).

\subsection{Planning the journey}

Efficient navigation requires making decisions about how to reach a given destination while satisfying various constraints such as avoiding having to walk overly long distances or avoiding barriers (Salthouse and Siedlecki, 2007). This ability is typically tested with laboratory tasks such as the multiple errand test (Shallice and Burgess, 1991) or the zoo map task (Wilson et al., 1996), which require using a map provided to carry out certain activities (e.g., shopping, visiting people). Older adults are generally found to be less efficient than young ones at determining the complex course of actions needed to reach the predefined goal; they make more mistakes and take more time to prepare the journey (Allain et al., 2005; Sander and Schmitter-Edgecombe, 2012). These findings are problematic, because before navigating to an unfamiliar place, older pedestrians often plan their journey on a map in order to reduce 
the risk of getting lost and the anxiety that ensues (Phillips et al., 2013). Age-related planning deficits are not as great, however, for more common tasks (e.g., Garden et al., 2001; Phillips et al., 2006), which are more similar to daily life situations in a familiar environment. This suggests that life-span experience in wayfinding at least partly compensates for some of the age-related cognitive declines that affect planning (Kliegel et al., 2007).

In planning their journeys, older adults are not always influenced by the desire to reduce the distance traveled on foot. The shortest way is not necessarily the chosen one, since several factors linked to physical accessibility and comfort may affect route choice in familiar environments. For example, older pedestrians have been shown to be more likely walk along streets with wide, comfortable sidewalks and no hills or stairs, and along streets with pedestrian devices such as zebra crossings or traffic-free zones (e.g., Borst et al., 2008; Mollenkopf et al., 1997; Ståhl et al., 2008). Moreover, older adults report a preference for roads with little car and pedestrian traffic because they are often afraid of being pushed (HugueninRichard, 2012). These safe choices are sometimes compromised, however, by illnesses that limit a pedestrian's walking distance and justify closer choices that are often not as safe (Bernhoft and Carstensen, 2008; Huguenin-Richard, 2012). Another point is the need for resting time, which increases the necessity of outdoor benches and seats with weather protection (Carlsson, 2004).

\subsection{Navigating and orientating}

The second key component of wayfinding is keeping track of one's direction and location while moving around in the environment. Globally, the ability to navigate and orientate oneself decline with aging (for reviews, see Klencklen et al., 2012; Moffat, 2009). This lesser efficiency, which leads to more errors and longer execution times, is observed not only in situations where a predefined plan exists (Sanders and Schmitter-Edgecombe, 2012; but see Allain et al., 2005), but also in the absence of a predefined plan, e.g., in real-life or in unknown virtual environments such as a medical center or a supermarket (e.g., Head and Isom, 2010; Kirasic, 1991; Wilkniss et al., 1997; Zakzanis et al., 2009).

This age-related decline has been explained in terms of difficulties selecting and learning the features needed to keep on course, and problems learning the temporospatial order of relevant landmarks (e.g., Wilkniss et al., 1997). The presence of prominent landmarks (e.g., post office, traffic lights) is helpful for older pedestrians navigating in both familiar and unfamiliar environments. In contrast, in a new environment, the use of a printed map providing an aerial view of the neighborhood seems to be less helpful for older adults than for younger ones (e.g., Goodman et al., 2005; Sjölinder et al., 2005). Recently, however, the opposite result was obtained by Yamamoto and DeGirolama (2012), who showed that some older adults are able to maintain their map-reading skills relatively well in unknown environments.

Many studies have also taken an interest in navigation strategies. A major distinction in these studies is the opposition between egocentric navigation (i.e., reference to spatial landmarks and one's current location and direction) and allocentric navigation (i.e., use of a mental map). Studies suggest the preferential use of egocentric rather than allocentric strategies among the elderly, probably due to spatial memory deficits and executive declines (for a review, see e.g., Taillade et al., 2014). The age-related impairment in the allocentric strategy, and also the ability to switch from egocentric route-following to allocentric wayfinding strategies seems to explain why older adults were outperformed by younger ones when trying to find novel shortcuts to attain a previously learned goal location in a realistic but virtual town environment (Harris and Wolbers, 2014).
Navigation in familiar environments appears to be less impaired with age than navigation in novel environments (Rosenbaum et al., 2012). Although the impact of familiarity on pedestrian navigation has not been studied much, some findings on older drivers suggest that they avoid unfamiliar routes (Bryden et al., 2013; Burns, 1999). Wayfinding tools offering “step-by-step" instructions and landmarks to follow could be an effective means of helping older people navigate in unfamiliar environments (e.g., Fickas et al., 2008; Goodman et al., 2005; May et al., 2003). These tools could at least partly compensate for age-related cognitive declines by reducing the cognitive load of navigation tasks. However, when asked about which kind of wayfinding strategies they used, 55.1\% of older drivers reported pulling over to check the map, but only 9.9\% reported regularly using a navigation system (Bryden et al., 2013). This reluctance to use navigation aids could be linked either to a lack of confidence in new technologies (e.g., Barnard et al., 2013) or to overloaded cognitive resources (e.g., divided attention) when using them to drive.

\section{Street crossing}

Crossing a street is a complex task that requires several actions (Bailey et al., 1992). First, pedestrians have to select an adequate crossing place, approach the curb, and look for oncoming vehicles and/or traffic lights. If there is no traffic light, pedestrians then have to select an adequate moment to cross by judging the available gaps in the flow of traffic. From there, they have to adapt their start-up time and crossing time to the amount of time available for crossing, by calibrating their walking speed to the visual feedback coming from approaching traffic.

\subsection{Selecting a place to cross}

Awareness of one's vulnerability with advancing age may explain why older pedestrians, as compared to younger ones, prefer to use pedestrian crosswalks and intersections with signals (Bernhoft and Carstensen, 2008). It should be noted that the risk of collision on crosswalks without signals is linked to incautious behavior on the part of pedestrians but also to the failure of drivers to stop at pedestrian crossings (Harruff et al., 1998; Koepsell et al., 2002).

Choosing a safe place to cross is particularly challenging for older pedestrians because they often suffer from physical impairments that reduce their ability to get to a pedestrian crossing that is too far away. Consequently, they sometimes even decide to "jaywalk", i.e., cross where there is no crosswalk. Despite their preference for crosswalks, the majority of older pedestrians report regularly crossing the street at their current position, especially when visibility is good or traffic is sparse (Bernhoft and Carstensen, 2008). This behavior is risky because complex road environments and infrastructures impose a high cognitive load as well as substantial physical demands on older pedestrians. This explains why the risk of accidents is higher, for example, in two-way traffic than in one-way traffic situations (Fontaine and Gourlet, 1997; Oxley et al., 1997). Older pedestrians' difficulty crossing wide streets or busy intersections may be caused by problems rapidly scanning traffic coming from various directions at the same time (Bernhoft and Carstensen, 2008).

\subsection{Exploration of the visual environment}

Accurate looking behavior to check for ongoing traffic is necessary for crossing streets safely. In the presence of a traffic light, the looking behavior of older and younger adults is quite similar (for a review, see Dunbar et al., 2004). In contrast, in the absence of a traffic light, the ability to assess crossing opportunities while 
approaching the street appears to decline with age. The decisionmaking process appears to be slowed, as suggested, for example, by the fact that older pedestrians pause on the sidewalk for a longer time before crossing (Oxley et al., 1997). This age effect is especially observed for crossing two-way streets, but not for one-way traffic situations (Oxley et al., 1997).

While older pedestrians seem to spend more time at the curb, the total number of head movements while waiting to cross appears to be similar in young and older pedestrians. This was observed in a field study by Oxley et al. (1995) and in a simulated streetcrossing task by Dommes et al. (2014). More specifically, older women were shown to look both ways less often than younger adults and older men did, although this gender effect seems to decrease with driving experience (Holland and Hill, 2010). A difference between older women with and without driver's license could be due to driving-related knowledge: driving experience may have an impact on a number of crossing skills such as visual searching (Underwood et al., 2002) and judging vehicle arrival times (Carthy et al., 1995). But a cohort effect resulting from socio-economic and educational differences could also explain this gender effect, insofar as the oldest women recruited in recent studies generally never learned how to drive, and driving was most often reserved for men in these generations. This generation effect is tending to disappear today because young and middle-aged women now drive as much as men. In any case, these overall findings suggest that older pedestrians have trouble processing a large amount of information at the same time and need more time to decide on the right moment to cross. Consequently, the similar number of head movements by young and older adults does not guarantee that the quality of the information taken in when exploring the visual scene is spared in older pedestrians. The study of the number of head movements may therefore not be sufficient to assess the efficiency of looking behaviors. Direction of gaze, the number and type of objects checked in the visual scene, looking time, and the speed of head movements may be more informative for assessing scanning behavior with aging.

\subsection{Choosing a time gap for crossing}

Choosing a safe time gap for crossing involves determining whether the time available between two vehicles exceeds the time needed to cross. This comparison requires assessing both the arrival time of the approaching vehicles and one's own crossing time (see also Section 5.4).

Two studies comparing the street-crossing decisions of different age groups revealed that older adults ( $70-80$ years old) chose a larger median time gap than younger ones did (20-30 and 60-70 years old) for crossing a simulated one-way street (Lobjois and Cavallo, 2007, 2009). This finding suggests that older pedestrians attempt to compensate for their slower walking speed. But several virtual-reality studies have also shown that older adults' decisions are biased by the approaching vehicle's speed and that the accepted time gap drops as speed increases, leading to smaller safety margins and more unsafe decisions when vehicle speed is high (Dommes and Cavallo, 2011; Lobjois and Cavallo, 2007, 2009; Oxley et al., 2005). Older pedestrians seem to use simplified heuristics based on vehicle distance: for a given available time gap, older people more often decide to cross when vehicles are moving at high speeds than at low ones because the distance of the approaching cars is also greater. They overestimate the time available for crossing and thus are more likely to experience difficulties.

A detailed investigation of accident statistics also suggests that older pedestrians are more likely to get hit on the far side than on the near side of a two-way street (Fontaine and Gourlet, 1997; Oxley et al., 1997; Dommes et al., 2014; Dommes et al., 2015). The greater risk on the far-side of the street seems to be partly explained by the slow walking speed of the elderly (Hoxie and Rubenstein, 1994): the far lane may have been clear when the crossing was initiated but becomes busy before it is completed. An additional explanation is related to inadequate judgments of far-side traffic. A simulator study investigating visual exploration strategies suggested that older pedestrians make crossing decisions mainly on the basis of the gap available in the near lane, while neglecting the far lane (Dommes et al., 2014). However, other studies have shown that pedestrians, and particularly the oldest ones, are more often involved in accidents in the early part of the crossings (Dunbar, 2012, 2005; Ward et al., 1994). The relative riskiness of near-side accidents seems to follow a reverse J-shaped curve across the lifespan, falling in late childhood and continuing fall until it rises again after age 85 (Dunbar, 2012). The risk of near-side accidents has also been shown to be high in pedestrians suffering from dementing diseases such as Alzheimer's disease (Gorrie et al., 2008). This risk may be due to attentional failures affecting the ability to check and effectively detect potential hazards, even on the near side of a two-way street.

\subsection{Start-up time and crossing time}

Start-up time corresponds to the time between the decision to cross and the first step into the street. A slow start-up will delay the crossing and increase the risk of still being on the road when a vehicle arrives. In laboratory tasks, start-up time is rarely isolated from measures of crossing time or decision-making time (see e.g., Oxley et al., 2005), or measures of initiation time (time between the moment when the pedestrian begins to cross and when the car opening the gap passes in front of him/her, see Lobjois and Cavallo, 2007, 2009; Holland and Hill, 2010). In a series of field studies, Knoblauch et al. (1996) observed that the start-up times of pedestrians waiting for a green walk sign were slightly longer for older adults than for younger ones: the average time was $1.9 \mathrm{~s}$ for younger adults and $2.5 \mathrm{~s}$ for older ones. Similarly, observations of real-life crossing behaviors (Oxley et al., 1997) as well as results from indoor experiments (Holland and Hill, 2010) have also revealed that older pedestrians take about $1 \mathrm{~s}$ longer than younger adults do. This increase may be due to the slowing of motor speed and reaction time with aging (Oxley et al., 1997), but also to the agerelated increase in decision-making time in adults age 75 years or over (Oxley et al., 2005).

\subsection{Calibration of walking speed to traffic perception}

After starting to cross the street, pedestrians can still make some adjustments (i.e., increasing or decreasing their walking speed) based on visual feedback provided by approaching vehicles. Walking-speed adaptation is probably an important factor that helps avoid collisions during street crossing. To maintain a satisfactory safety margin, young pedestrians have been shown to increase their walking speed during simulator experiments when ever the time gap between vehicles decreases, whereas this adjustment is not observed in older pedestrians (Dommes et al., 2014; Lobjois and Cavallo, 2009). Lobjois and Cavallo (2009) suggested that the crossing decisions of younger adults are much more finely tuned to time gaps because they use visual feedback while crossing. Older adults may have trouble calibrating perception and action. Dommes et al. (2014) also observed few chances for compensation by walking faster. Beyond the well-known motor declines with aging (see e.g., Shkuratova et al., 2004), the absence of compensation for decision-making errors by walking quickly could also be linked to old people's need to visually control their gait and balance; this prevents them from watching approaching traffic while walking. Several studies have clearly shown that old people need to watch their feet to avoid a fall while walking (see e.g., Avineri et al., 
2012). This sensorimotor-performance priority (see e.g., ShumwayCook et al., 1997) is likely to be detrimental to the visual monitoring of approaching vehicles (see Section 2.1).

\section{Functional changes affecting older pedestrians' safety}

Many components of pedestrian activity are affected by the normal aging process and may therefore have a negative impact on older pedestrians' safety and mobility. These overall functional changes pertain to sensory, cognitive, and physical abilities, as well as self-perception.

\subsection{Impact of sensory changes}

Because walking, navigating and street crossing are highly visual (for a review, see Shinar and Schieber, 1991), the visual declines associated with the normal aging process and age-related diseases like cataract, glaucoma, and macular degeneration, may be important factors in explaining the greater mobility difficulties of older pedestrians, such as their increased likelihood of making unsafe crossing decisions. Whereas the effect of vision loss on safety has been investigated much more often in older drivers than in older pedestrians, some data are available. The risk of falling increases with declines in visual acuity (for a review, see Harwood, 2001; Ivers et al., 1998), adaptation to the dark (McMurdo and Gaskell, 1991), the binocular visual field (Coleman et al., 2007; Freeman et al., 2007), and contrast sensitivity (Ivers et al., 1998; Lord et al., 1991). Visual acuity loss has also been shown to cause problems in discriminating vehicles from the rest of the road environment (Oxley et al., 1995), and declines in contrast sensitivity are thought to hinder the perception of fixed or moving objects such as sidewalks or oncoming vehicles (Oxley et al., 1995). The decline of visual motion sensitivity in older adults (e.g., Sekuler et al., 1980; Snowden and Kavanagh, 2006) has been proposed to directly account for the use of distance-based heuristics and the ensuing increase in unsafe crossing decisions when vehicles moving at a high speed are approaching a pedestrian crossing the street on a full-scale simulator (Dommes et al., 2013; Dommes and Cavallo, 2011; Lobjois and Cavallo, 2007): the slow angular velocity of the vehicles is difficult to perceive and is even sometimes below the perceptual threshold, causing vehicle speed information to be neglected.

Regarding pathological age-related changes, the risk of falling is greater in the presence of glaucoma (Haymes et al., 2007), macular degeneration (Szabo et al., 2008), and cataract (McCarty et al., 2002). It is not completely clear yet whether cataract surgery reduces this increased risk of falling (for a review, see Desapriya et al., 2010). Finally, glaucoma is associated with poorer selfreported mobility (Black et al., 2011; Friedman et al., 2007).

Vision is not the only sensory modality that declines in older people. Hearing loss also increases with aging. Around $30-75 \%$ of adults age 75 or over present a hearing loss, according to the definition currently in effect (Salonen et al., 2011; Smith et al., 2008). Although hearing impairment could have a significant impact on pedestrian safety, investigations are scarce compared to studies on vision. Hearing may help in the spatial localization of vehicles, so older people with hearing impairments may have trouble locating approaching vehicles coming from behind them or turning (for a review, see Dunbar et al., 2004). In one study using questionnaires (Holland and Rabbitt, 1992), older adults who felt their hearing had deteriorated over the past few years were shown to report avoiding walking along streets with no sidewalks. Hearing impairments, moreover, have been proven to be clearly associated with a larger risk of falling (Grue et al., 2009; Lopez et al., 2011), poorer selfreported physical health (Lopez et al., 2011), and poorer general mobility (Viljanen et al., 2009). A diminished auditory capacity is also likely to have a negative impact on street-crossing safety: the absence of auditory information, as studied in a simulator experiment, has been shown to give rise to more risky street-crossing decisions in both young and old pedestrians (Rodrigues et al., 2012).

In addition to the visual and auditory systems, the proprioceptive and vestibular systems are involved in standing upright and moving through space. Efficient postural regulation requires integrating high quality sensory information coming from somatosensory, visual, and vestibular afferences (Gauchard et al., 2001). The age-related decline of proprioceptive and vestibular afferences appears to account for the impaired sense of balance and the increased risk of falling found in older pedestrians (see e.g., Gauchard et al., 2001; Patel et al., 2010). For example, older adults are hindered more than younger adults by vibrations of skeletal muscles or tendons (Patel et al., 2010) or by visual distortions while walking (Huitema et al., 2005). More generally, an increase in the task demands imposed on the proprioceptive and vestibular systems (i.e., closed eyes, movement of the experimental room) is associated with more body sways among older than young adults (Prioli et al., 2006).

\subsection{Impact of cognitive changes}

One of the most striking age-related declines is in processing speed, i.e., the rate at which the brain and nervous system can process sensory information (Salthouse, 1996). This decrease in processing speed has been shown to be associated with a slow walking speed and a higher risk of falling (Holtzer et al., 2007; Owsley and McGwin, 2004; Rosano et al., 2012; Welmerink et al., 2010). A slower processing speed may also partly explain poorer navigation performance with aging (Kliegel et al., 2007; Salthouse and Siedlecki, 2007). Finally, because processing speed is necessary for making timely, correct decisions, it could also explain the longer start-up times of older pedestrians, as well as the link observed between the safeness of street-crossing decisions made in simulator experiments and scores on the UFOV ${ }^{\circledR}$ test (Dommes and Cavallo, 2011; Dommes et al., 2013, 2015). The UFOV ${ }^{\circledR}$ test is a computer-based test of rapid visual-scene perception that measures the useful field of view (i.e., the area from which one can extract visual information at a brief glance without head or eye movements) and therefore involves processing speed and visual attention (Ball and Owsley, 1993).

Another main cognitive change with aging is the decline of executive functions, i.e., the capacity for updating and monitoring information in working memory, inhibiting inconsistent or useless information, and shifting (Salthouse et al., 2003). Inhibition declines have been shown to be associated with a greater number of falls (Anstey et al., 2009). This association can be explained by the role of inhibition on gait control and multitask coordination (for a review, see Liu et al., 2014). More incorrect decisions have also been observed on a full-scale street-crossing simulator with inhibition declines (Dommes and Cavallo, 2011). Likewise, the age-related decline of the ability to switch lines of reasoning and actions in order to perceive, process, and respond to situations in a flexible way (i.e., shifting skills) have been shown to be a significant predictor of street-crossing collisions (Dommes et al., 2013): in a complex, two-way street environment, older pedestrians with poor shifting skills seem to have difficulty switching their attention between traffic approaching from two different directions, and selecting the most relevant information sources.

The impact of executive functions on road safety has often been investigated using the dual-task paradigm, which requires performing two tasks at the same time. In reality, instead of doing several tasks simultaneously, the individual has to quickly shift back and forth between the two tasks (Hawkes et al., 2012). The 
concomitant accomplishment of a secondary task, such as a memory task or producing spontaneous speech, is generally associated with slower walking speed (Lindenberger et al., 2000; PlummerD'Amato et al., 2011), narrower safety margins when stepping over obstacles while walking (Harley et al., 2009), an increased risk of falling (Faulkner et al., 2007; Lundin-Olsson et al., 1997), and streetcrossing impairments such as a greater risk of being hit and longer crossing times (Nagamatsu et al., 2011; Neider et al., 2011). These negative consequences on mobility and safety are greater in older than in young adults, and suggest that walking is no longer automatic with aging: it requires additional attentional resources (e.g., Laessoe et al., 2008; Sheridan and Hausdorff, 2007) and the involvement of executive functions (for reviews, see Al-Yahya et al., 2011; Beurskens and Bock, 2012). Older adults have been shown to place priority on motor control during dual-task walking, so as to avoid falling but at the expense of walking speed (Hollman et al., 2007) or talking (for a review, see Beurskens and Bock, 2012; Sparrow et al., 2002). In this line, the greater declines of executive functions in mild cognitive impairment and Alzheimer's disease (da Costa et al., 2013) may be why these medical conditions are strongly associated with a higher risk of falling (Delbaere et al., 2012; Sheridan and Hausdorff, 2007), a higher risk of being injured during street crossing (Gorrie et al., 2008) and navigation difficulties in real-life or simulator studies (e.g., Kliegel et al., 2007; Salthouse and Siedlecki, 2007; Taillade et al., 2013).

Last but not least, memory difficulties - one of the most important complaints of older people - have a major impact on spatial navigation (for a review, Klencklen et al., 2012). In a study by Gras et al. (2012), older adults were shown to be slower and less accurate than younger ones in real route learning. This poorer performance was in part explained by episodic-memory and working-memory declines. The decline in visuo-spatial working memory with aging could be linked to a reduced ability to inhibit irrelevant information that uses up some of the working-memory resources ${ }^{1}$ needed to learn complex new routes (Mammarella et al., 2009). Difficulty learning new routes and disorientation are greater and more prevalent in patients suffering from mild cognitive impairment (Cushman et al., 2008; Hort et al., 2007) or Alzheimer's disease (Liu et al., 1991; Rainville et al., 2001; Zakzanis et al., 2009).

\subsection{Impact of physical changes}

Mobility and safety are also challenged by age-related physical changes affecting muscles, bones, and joints. Skeletal muscle mass and strength are highly affected by these changes, with a decrease during aging while the proportion of body fat increases (Spirduso et al., 2005; Fakhouri et al., 2012; for a review, see Visser, 2011). The decline of muscle strength with age is associated with slower walking and standing up from a sitting position (Asher et al., 2012; Spirduso et al., 2005), and an increase in the risk of falling (Landi et al., 2012; Pijnappels et al., 2008). Obesity, often concurrent with the decline of skeletal muscle mass, is also associated with a higher risk of acquiring walking disabilities (Stenholm et al., 2007) and falling (Fjeldstad et al., 2008; Himes and Reynolds, 2012). However, fat loss by caloric restriction during aging may lower muscular strength and bone mass by causing under-nutrition (see the review by Miller and Wolfe, 2008). Consequently, an increase in physical activity should be preferred, accompanied by nutritional supervision (for a review, see Darmon, 2013).

The low bone mineral density associated with osteoporosis increases with aging and represents an important fall-related

\footnotetext{
1 According to the literature review by Hasher and Zacks (1988), inefficient inhibitory mechanisms will allow more irrelevant information to enter working memory, overloading its storage capacity.
}

risk of fracture, notably in older women (Harris, 2002; Lips and Van Schoor, 2005). Another risk of osteoporosis is that it exacerbates the over-curvature of the thoracic vertebrae, a condition called kyphosis (Arnold et al., 2005). Kyphosis increases during aging, and excessive kyphosis is associated with poor walking and stair-climbing performance, poor postural control during obstacle avoidance, and a higher risk of falling (Arnold et al., 2005; Katzman et al., 2011; Sinaki et al., 2005). Kyphosis could also have a negative effect on visual exploration of the environment during street crossing because of the associated impairment of cervical mobility (Quek et al., 2013). Similarly, osteoarthritis, a common inflammatory joint disorder in older people, is associated with difficulty walking and climbing stairs, as well as a higher risk of falling (Guccione et al., 1990; Hanlon et al., 2002; Hochberg et al., 1995).

\subsection{Impact of self-perception and self-regulation}

An age-related awareness of one's reduced functional abilities and frailty in the street is an important element of self-regulation that may help older people adjust their behavior accordingly. More specifically, people aware of their limitations can use selfregulation to deal with the environmental demands. Conversely, individuals who lack awareness of their failing abilities and limitations are shown to be more at risk of engaging in behaviors that compromise their safety (Marottoli and Richardson, 1998).

The self-perception of age-related walking-speed reductions may prompt self-regulatory behaviors. It may also explain why older pedestrians prefer to use signalized pedestrian crossings more than do young pedestrians (Bernhoft and Carstensen, 2008). However, older adults often underestimate the time they need to cross the street: their actual crossing times are significantly longer than the crossing times they estimate before or after crossing (Naveteur et al., 2013; Zivotofsky et al., 2012). This kind of underestimation occurs especially for younger older adults (60-74 years old) whereas older adults ( 75 years old or more) tend to overestimate their crossing time (Holland and Hill, 2010).

Awareness of one's declining eyesight is also useful for developing self-regulation behaviors. Using a questionnaire, Holland and Rabbitt (1992) showed that older pedestrians who felt that their eyesight had deteriorated over the past 10 years avoided crossing the street at night. Older pedestrians who perceived difficulties seeing in the dark or at dusk reported avoiding crossing the street outside a pedestrian crosswalk and walking along a street with no sidewalk. Older pedestrians who reported difficulties seeing in bright light or glare declared avoiding crossing the street under these conditions, and finally, older pedestrians who reported difficulty reading road signs tended to say they avoided crossing at complex intersections, crossing outside a pedestrian crosswalk, and crossing with the sun in their eyes.

Impaired postural control is also known to provoke several kinds of self-regulation. With aging, as the risk of falling grows, the fear of falling increases too (for a review, see Legters, 2002). Overall, older people with fear of falling avoid situations known to be difficult to handle or with a high risk of falling (for a review, see Zijlstra et al., 2007). For example, compared to older pedestrians who are less afraid of falling, ones who are more afraid have been shown to look more at the pavement and their footsteps, and therefore pay less attention to crossing in traffic (Avineri et al., 2012). Older pedestrians are especially looking for sidewalks along their route and smooth surfaces for walking (Bernhoft and Carstensen, 2008). As a consequence, and somewhat counterintuitively, older pedestrians often express concerns about falling or feeling unstable on tactile paving close to footpaths or stairs to assist blind and visionimpaired pedestrians (I'DGO, 2010) and some of them prefer to walk around it. Paved streets and sidewalks, which are frequent in European cities, are probably associated with the same concerns 
and reluctance. Another topic of concern is pavements that are slippery due to rain, dry leaves or snow. Older pedestrians have been shown to be worried about ice and/or snow on sidewalks (Wennberg et al., 2009) and walk more slowly when it is snowing (Knoblauch et al., 1996).

It is not easy to determine how accurate these fears and selfperceptions are. Self-evaluation accuracy is important because inaccurate self-perceptions may have negative consequences on the mobility and safety of older people. According to Tinetti and Powell (1993), 48\% of older adults age 75 years or older who had fallen within the previous year reported fear of falling, but $27 \%$ of those who had not fallen did also. Previous falls thus seem to be linked to an increase in the fear of falling, but not strictly. Some studies have actually suggested that the gait-parameter changes observed with aging are better explained by the fear of falling or aging stereotypes than by aging itself (see Chamberlin et al., 2005).

\section{Recommendations for improving safety and mobility}

The studies reviewed above have shed light on the main causes of older adult pedestrian's high rate of involvement in fatalities and injuries. Some of these factors are linked to the road user him/herself (i.e., declines in sensory, cognitive, and physical abilities, and incorrect estimation of one's own capabilities). Risk factors linked to the road environment play an important role too (e.g., complexity of road infrastructures, vehicle speed). However, despite this accumulated knowledge, little empirical evidence has been published about how to help older pedestrians more particularly.

\subsection{Training programs for older pedestrians}

One of the most direct ways of enhancing older pedestrians' safety is to try to modify their behaviors and strategies through training. However, systematic evaluations or even attempts to examine training efficiency are still scarce and require further investigation.

Physical declines are targeted by training programs aimed at improving balance, flexibility, velocity, and cardiovascular function. Such gains, with long-term effects, have been observed after training via heavyweight muscle exercises, stretching, Tai-chi movements, and/or walking programs (Cristopoliski et al., 2009; Gatts and Woollacott, 2006; Giné-Garriga et al., 2010; for a review, see Granacher et al., 2008; Malatesta et al., 2010). The reported benefits of physical training programs on gait and balance could improve the safety and mobility of older pedestrians, particularly by decreasing both the risk and the fear of falling outside of the home, and maybe by increasing walking speed for crossing the street. In the present state of our knowledge, physical exercise appears to be one of the most efficient approaches for older pedestrians. Recent papers have shown in particular that engagement in physically simulated sport games enhances the cognitive and physical abilities directly involved in the daily living activities of older adults (Maillot et al., 2012). The beneficial effects of physical exercise on cognitive performance in older adults have been clearly established (see e.g. the meta-analytic reviews by Colcombe and Kramer, 2003, and Angeraven et al., 2008). In contrast, supporting evidence of the impact of cognitive training for older pedestrians is still scarce, although some training programs targeting older drivers have indicated some benefits (e.g., Roenker et al., 2003). However, a recent study using UFOV-training of older pedestrians, while significantly enhancing processing speed and the useful field of view, did not produce notable improvements in the acceptance of safe gaps (Cavallo and Dommes, 2014).
Unlike physical and cognitive training programs which are aimed at improving the abilities and skills of older pedestrians, the objectives of educational and behavioral programs is to make pedestrians more aware of their possible limitations and of what safe behaviors they should adopt. Regarding fall prevention, educational programs are generally combined with some other kind of training (e.g. physical training), which seems to effectively enhance knowledge of the risk of falling (Schepens et al., 2011). Until now, and despite several local and governmental initiatives (for a review, see Dunbar et al., 2004), only one study has found evidence that educational training can improve the safety of older adults' streetcrossing decisions (Cavallo and Dommes, 2014). Note that studies on older drivers have shown that educational programs improve knowledge, but the existence of safety benefits has not been proven (for a review, see Korner-Bitensky et al., 2009). Consequently, more studies that evaluate the effectiveness of educational interventions are required for older pedestrians.

Another approach is to combine educational programs with behavioral training that directly addresses behavior and know-how through repeated practice in real or simulated environments. In recent years, studies aimed at training people through the use of simulators and virtual reality have emerged in the field of road safety. These tools have already proven powerful as training devices for preventing child pedestrian injury (e.g., McComas et al., 2002; Thomson et al., 2005) or for teaching basic driving skills to older adults (for a review, see Boot et al., 2014). But for older pedestrians, behavioral training studies using virtual reality are still rare. Two recent simulator studies combining repeated street crossings, explicit feedback, and discussions obtained positive effects on the safety of older pedestrians' crossing decisions (Dommes and Cavallo, 2012; Dommes et al., 2012). It has even been shown that behavioral training on a simulator alone can make for safer gap acceptance levels during street-crossing (Cavallo and Dommes, 2014). In another recent training program, older adults were taught to judge vehicle speed more accurately and were found to improve gap-acceptance accuracy in real-world conditions (Hunt et al., 2011). However, that experiment had no follow-up phase or control group and did not include an actual crossing. Future longitudinal studies should go beyond these methodological limitations in order to determine whether this kind of method can successfully promote long-term improvements in older adults' street-crossing behaviors. This being said, aging may be associated with rigid strategies and habits that are difficult to change (Rosenbloom et al., 2015), as highlighted by a study that failed to improve on-road hazard detection in older pedestrians.

Finally, interventions should also be geared to other road users, not just older adults. The safety of pedestrians requires safe behaviors from all road-user groups. More respectful behaviors, especially toward older people and disabled individuals, could be increased by media campaigns and local or national government actions (Boyce and Geller, 2000; Van Houten et al., 1985). Not stopping for pedestrians at crosswalks should be regarded as a serious offense punishable by severe fines, just like other road violations.

\subsection{Ergonomic design of road environments and cars}

There are a number of improvements in road environments that could decrease the risk of falls and collisions, and also promote the mobility of older pedestrians. Wide, flat, non-slippery sidewalks without obstacles reduce the risk of falling (Bernhoft and Carstensen, 2008; Liu, 2015). Leaves and snow should be removed promptly from sidewalks and crosswalks. In addition, the investigation of alternative designs for pedestrian ramps is required to prevent the bottom of the ramps from pooling with rain or ice ( $\mathrm{Li}$ et al., 2013). Another important point for urban designers is to check for the presence of a sufficient number of resting places (i.e., seats, 
benches) as well as public restrooms (Carlsson, 2004). The provision of shady resting places and water fountains is particularly important for hot summer days.

Regarding navigation and the fear of getting lost, signs giving directions and other indications should be included by urban planners and designers (Phillips et al., 2013). These could include signs showing distances, the purpose of various places, and important landmarks. Navigation in new places by people with cognitive impairments could be greatly improved by the use of high-quality GPSs indicating significant landmarks and step-by-step orientating instructions. However, these technological tools must be carefully designed to avoid a sensory and/or cognitive overload for older users. For example, too many cognitively demanding devices have been shown to increase gait irregularities in older adults (see e.g. Schellenbach et al., 2010). Consequently, GPSs need to be flexible and specifically designed for and tested on older adults, not only by assessing their navigational benefits but also by examining their possible negative impact on other areas of the older pedestrian activity such as balance and cognitive resources (Schellenbach et al., 2010).

Safety and comfort during street crossing could also be improved by providing a sufficient number of well-designed and well-placed crosswalks (Koepsell et al., 2002). In the case of crosswalks without traffic signals, the presence of car-free islands in the middle of two-way streets is recommended because it allows pedestrians to cross in two stages and thereby lightens the cognitive load (Dommes et al., 2014; ITF, 2012). Crosswalks with traffic signals should be preferred, however. The presence of countdown displays giving the time left for crossing is an effective way of providing feedback to older pedestrians. Previous studies have shown that countdown displays increase the traffic-signal compliance of older pedestrians (Lipovac et al., 2013). Overall, the time allowed by traffic lights for pedestrians to cross the street has been shown to be insufficient for most older people (Amosun et al., 2007; Asher et al., 2012; Hoxie and Rubenstein, 1994). The need to hurry is frequent in older adults and is associated with anxiety, despite the presence of traffic lights (Amosun et al., 2007; Hoxie and Rubenstein, 1994) and this may provoke reluctance to cross. Traffic lights should therefore be designed to offer older adults enough time to cross safely and calmly.

Another efficient action is to use sidewalks that extend out to the edge of the parking lane. This reduces the distance to cross and consequently the time spent in the street (ITF, 2012). Speed-reduction measures for cars, such as speed ramps or street narrowing, are also promising ways to decrease the risk of collision (Dommes and Cavallo, 2011) and the gravity of injuries when a pedestrian is hit (Rosén and Sander, 2009).

Finally, improving on-board technologies and the design of cars (bumper, hood, windshield) are other means of improving the safety of older pedestrians (Jermakian, 2011; for a review, see Crandall et al., 2002).

\section{Conclusion}

Walking is the cheapest, easiest, and most sustainable way to get around. Every trip begins and ends by walking, which is the common link in the multimodal travel chain. While walking is the most common transportation mode used by older people, it is also a particularly risky activity for this population. Although population aging and urbanization, and in particular the development of "global age-friendly cities" (WHO, 2007), have been identified as two of the most important challenges of the present century, research and public policy within the past few decades have focused on older drivers, thereby neglecting older pedestrians and their travel requirements. More generally, there is still an important need in our developed societies to recognize the significance of mobility for older people, and to better understand not only the mobility changes that occur in later life, but also the ability of the elderly to stay mobile through normal and pathological aging.

To answer the aging challenge, along with issues linked to climate change, pollution, and health in general, public authorities should help older people's travel in a "multimodal", "sustainable", and "adapted" way, i.e., by ensuring the greater and safer use of walking and public transportation, and also the controlled use of individual cars.

In future research, it would be worthwhile to further investigate the impact of functional declines, and especially older people's awareness of their declining abilities and their positive and negative effects on safety and mobility. This knowledge will permit the implementation of efficient and suitable programs aimed at older pedestrians and road environments.

A lot remains to be accomplished in the area of effectively assessing the actions taken. An increasing number of local and governmental initiatives are being implemented to address older pedestrian safety (e.g., modification of infrastructures and equipment, educational training) but most of them have not been evaluated in a systematic way. As mentioned by Husband (2010) in a review regarding a similar problem for older drivers, the lack of evaluation may be due to time constraints or insufficient knowledge or resources. This situation highlights the need to tighten the link between researchers and local and governmental authorities so that interventions will be systematically and objectively evaluated, using a valid methodology. Cooperation between research and transportation-related public policy-makers is a necessary part of improving the ability of older adults to remain mobile and safe, which is essential to their well-being, autonomy, and social integration.

\section{Acknowledgements}

The work was funded by DG Move, through the SAMERU project (agreement number MOVE/SUB/2010/D3/300-1/SI2.565668SAMERU), aimed at investigating the safety and mobility of elderly road users. The authors would like to thank Vivian Waltz for the English editing.

\section{References}

Abou-Raya, S., ElMeguid, L.A., 2009. Road traffic accidents and the elderly. Geriatr Gerontol. Int. 9, 290-297.

Al-Yahya, E., Dawes, H., Smith, L., Dennis, A., Howells, K., Cockburn, J., 2011 Cognitive motor interference while walking: a systematic review and meta-analysis. Neurosci. Biobehav. Rev. 35, 715-728.

Allain, P., Nicoleau, S., Pinon, K., Etcharry-Bouyx, F., Barré, J., Berrut, G., Dubas, F., Le Gall, D., 2005. Executive functioning in normal aging: a study of action planning using the Zoo Map Test. Brain Cogn. 57, 4-7.

Alexander, N.B., 1996. Gait disorders in older adults. J. Am.Geriatr. Soc. 44, 434-451.

Amosun, S.L., Burgess, T., Groeneveldt, L., Hodgson, T., 2007. Are elderly pedestrians allowed enough time at pedestrian crossings in Cape Town, South Africa? Physiother. Theory Pract. 23, 325-332.

Anstey, K.J., Wood, J., Kerr, G., Caldwell, H., Lord, S.R., 2009. Different cognitive profiles for single compared with recurrent fallers without dementia. Neuropsychology 23, 500-508.

Angeraven, M., Aufdemkampe, G., Verhaar, H.J., Aleman, A., Vanhees, L., 2008 Physical activity and enhanced fitness to improve cognitive function in older people without known cognitive impairment. Cochrane Database Syst. Rev. (Online), 16

Arango, J., Montufar, J., 2008. Walking speed of older pedestrians who use canes or walkers for mobility. Transp. Res. Rec. 2073, 79-85.

Arnold, C.M., Busch, A.J., Schachter, C.L., Harrison, L., Olszynski, W., 2005. The relationship of intrinsic fall risk factors to a recent history of falling in older women with osteoporosis. J. Orthop. Sports Phys. Ther. 35, 452-460.

Asher, L., Aresu, M., Falaschetti, E., Mindell, J., 2012. Most older pedestrians are unable to cross the road in time: a cross-sectional study. Age Ageing 41 690-694. 
Avineri, E., Shinar, D., Susilo, Y.O., 2012. Pedestrians' behaviour in cross walks: the effects of fear of falling and age. Accid. Anal. Prev. 44, 30-34.

Bailey, S.S., Jones, S.A., Stout, R.J., Bailey, J.H., Kass, S., Morgan, B.B., 1992. Issue of elderly pedestrians. Transp. Res. Rec. 1375, 68-73.

Ball, K., Owsley, C., 1993. The useful field of view test: a new technique for evaluating age-related declines in visual function. J. Am. Optometric Assoc. 64 (1), 71-79

Barnard, Y., Bradley, M.D., Hodgson, F., Lloyd, A.D., 2013. Learning to use new technologies by older adults: perceived difficulties, experimentation behaviour and usability. Comput. Hum. Behav. 29, 1715-1724, http://dx.doi. org/10.1016/j.chb.2013.02.006.

Bernhoft, I.M., Carstensen, G., 2008. Preferences and behaviour of pedestrians and cyclists by age and gender. Transp. Res. Part F: Traffic Psychol. Behav. 11, $83-95$

Beurskens, R., Bock, O., 2012. Age-related deficits of dual-task walking: a review. Neural Plast., http://dx.doi.org/10.1155/2012/131608.

Blake, A.J., Morgan, K., Bendall, M.J., Dallosso, H., Ebrahim, S.B., Arie, T.H., Fentem, P.H., Bassey, E.J., 1988. Falls by elderly people at home: prevalence and associated factors. Age Ageing 17, 365-372.

Black, A.A., Wood, J.M., Lovie-Kitchin, J.E., 2011. Inferior visual field reductions are associated with poorer functional status among older adults with glaucoma. Ophthalmic Physiol. Opt. 31, 283-291.

Boot, W., Stothart, C., Charness, N., 2014. Improving the safety of aging road users: a mini-review. Gerontology 60, 90-96.

Borst, H.C., Miedema, H.M.E., de Vries, S.I., Graham, J.M.A., van Dongen, J.E.F., 2008. Relationships between street characteristics and perceived attractiveness for walking reported by elderly people. J. Environ. Psychol. 28, 353-361.

Boyce, T.E., Geller, E.S., 2000. A community-wide intervention to improve pedestrian safety. Guidelines for institutionalizing large-scale behavior change. Environ. Behav. 32, 502-520.

Bryden, K.J., Charlton, J.L., Oxley, J.A., Lowndes, G.J., 2013. Self-reported wayfinding ability of older drivers. Accid. Anal. Prev. 59, 277-282.

Buckley, T., Pitsikoulis, C., Barthelemy, E., Hass, C.J., 2009. Age impairs sit-to-walk motor performance. J. Biomech. 42, 2318-2322.

Burns, P.C., 1999. Navigation and the mobility of older drivers. J. Gerontol.: Ser. B: Psychol. Sci. Soc. Sci. 54B, S49-S55.

Campbell, A.J., Borrie, M.J., Spears, G.F., et al., 1989. Risk factors for falls in a community-based prospective study of people 70 years and older. J. Gerontol. 44, 112-117.

Cao, C., Schultz, A.B., Ashton-Miller, J.A., Alexander, N.B., 1998. Sudden turns and stops while walking: kinematic sources of age and gender differences. Gait Posture 7, 45-52.

Carlsson, G., 2004. Travelling by urban public transport: exploration of usability problems in a travel chain perspective. Scand. J. Occup. Ther. 11, 78-89.

Carthy, T., Packham, D., Salter, D., Silcock, D., 1995. Risk and Safety on the Roads The Older Pedestrian. Report Prepared for the AA Foundation for Road Safety Research. University of Newcastle upon Tyne, Newcastle upon Tyne.

Cavallo, V., Dommes, A., 2014. Can older pedestrians be trained to make safer street-crossing decisions? In: Paper Presented at the 28th International Congress of Applied Psychology, Paris, July.

Chamberlin, M.E., Fulwider, B.D., Sanders, S.L., Medeiros, J.M., 2005. Does fear of falling influence spatial and temporal gait parameters in elderly persons beyond changes associated with normal aging? J. Gerontol. Ser. A: Biol. Sci. Med. Sci. 60A, 1163-1167.

Colcombe, S.J., Kramer, A.F., 2003. Fitness effects on the cognitive function of older adults: a meta-analytic study. Psychol. Sci. 14, 125-130.

Coleman, A.L., Cummings, S.R., Fei, Y., Kodjebacheva, G., Ensrud, K.E., Gutierrez, P., Stone, K.L., Cauley, J.A., Pedula, K.L., Hochberg, M.C., 2007. Binocular visual-field loss increases the risk of future falls in older white women. J. Am. Geriatr. Soc. 55, 357-364.

Crandall, J.R., Bhalla, K.S., Madeley, N.J., 2002. Designing road vehicles for pedestrian protection. BMJ 324, 1145-1148.

Cristopoliski, F., Barela, J.A., Leite, N., Fowler, N.E., Rodacki, A.L.F., 2009. Stretching exercise program improves gait in the elderly. Gerontology 55, 614-620.

Cushman, L.A., Stein, K., Duffy, C.J., 2008. Detecting navigational deficits in cognitive aging and Alzheimer disease using virtual reality. Neurology 71 888-895.

da Costa, A.C.G., Porto, C.S., Nitrini, R., Dozzi Brucki, S.M., 2013. Ecological evaluation of executive functions in mild cognitive impairment and Alzheimer disease. Alzheimer Dis. Assoc. Disord. 27, 95-101.

Darmon, P., 2013. Intentional weight loss in older adults: useful of wasting disease generating strategy. Curr. Opin. Clin. Nutr. Metab. Care 16, 284-289.

Delbaere, K., Kochan, N.A., Close, J.C., Menant, J.C., Sturnieks, D.L., Brodaty, H., Sachdev, P.S., Lord, S.R., 2012. Mild cognitive impairment as a predictor of falls in community-dwelling older people. Am. J. Geriatr. Psychiatry 20, 845-853.

Desapriya, E., Subzwari, S., Scime-Beltrano, G., Samayawardhena, L.A., Pike, I., 2010. Vision improvement and reduction in falls after expedited cataract surgery: systematic review and metaanalysis. J. Cataract Refract. Surg. 36, 13-19.

Dommes, A., Cavallo, V., 2011. The role of perceptual, cognitive, and motor abilities in street-crossing decisions of young and older pedestrians. Ophthalmic Physiol. Opt. 31, 292-301.

Dommes, A., Cavallo, V., 2012. A simulator-based training method to improve older pedestrians' safety. Transp. Res. Part F: Traffic Psychol. Behav. 15, 206-218.

Dommes, A., Cavallo, V., Dubuisson, J.-B., Tournier, I., Vienne, F., et al., 2014. Crossing a two-way street: comparison of young and old pedestrians. J. Saf. Res. 50, 27-34.
Dommes, A., Cavallo, V., Vienne, F., Aillerie, I., et al., 2012. Age-related differences in street-crossing safety before and after older pedestrians' training. Accid. Anal. Prev. 44, 42-47.

Dommes, A., Cavallo, V., Oxley, J.A., 2013. Functional declines as predictors of risky street-crossing decisions in older pedestrians. Accid. Anal. Prev., http://dx.doi. org/10.1016/j.aap.2013.05.0173.

Dommes, A., Le Lay, T., Vienne, F., Dang, N.-T., Perrot Beaudoin, A., Do, M.C., 2015. Towards an explanation of age-related difficulties in crossing a two-way street. Accid. Anal. Prev. 85, 229-238.

Dunbar, G., 2005. Using epidemiological data to address psychological questions about pedestrian behaviour. In: Underwood, G. (Ed.), Traffic and Transport Psychology: Theory and Application. Elsevier, Oxford, pp. 19-25.

Dunbar, G., 2012. The relative risk of nearside accidents is high for the youngest and oldest pedestrians. Accid. Anal. Prev. 45, 517-521.

Dunbar, G.C., Holland, A., Maylor, E.A., 2004. Older Pedestrians: A Critical Review of the Literature. Department for Transport, London.

Espy, D.D., Yang, F., Bhatt, T., Pai, Y.C., 2010. Independent influence of gait speed and step length on stability and fall risk. Gait Posture 32, 378-382.

Fakhouri, T.H.I., Odgen, C.L., Carroll, M.D., Kit, B.K., Flegal, K.M., 2012. Prevalence of obesity among older adults in the United States, 2007-2010. NCHS Data Brief $106,1-8$.

Faulkner, K.A., Redfern, M.S., Cauley, J.A., Landsittel, D.P., Studenski, S.A., Rosano, C. Simonsick, E.M., Harris, T.B., Shorr, R.I., Ayonayon, H.N., Newman, A.B., 2007. Multitasking: association between poorer performance and a history of recurrent falls. J. Am. Geriatr. Soc. 55, 570-576.

Fickas, S., Sohlberg, M., Hung, P.-F., 2008. Route-following assistance for travelers with cognitive impairments: a comparison of four prompt modes. Int. J. Hum.-Comput. Stud. 66, 876-888.

Fjeldstad, C., Fjeldstad, A.S., Acree, L.S., Nickel, K.J., Gardner, A.W., 2008. The influence of obesity on falls and quality of life. Dyn. Med. 7, 4-10.

Fontaine, H., Gourlet, Y., 1997. Fatal pedestrian accidents in France: a typological analysis. Accid. Anal. Prev. 29, 303-312.

Fothergill, J., O’Driscoll, D., Hashemi, K., 1995. The role of environmental factors in causing injury through falls in public places. Ergonomics 38, 220-223.

Fox, K., Stathi, A., McKenna, J., Davis, M., 2007. Physical activity and mental well-being in older people participating in the Better Ageing Project. Eur. J. Appl. Physiol. 100, 591-602.

Freeman, E.E., Munoz, B., Rubin, G., West, S.K., 2007. Visual field loss increases the risk of falls in older adults: the salisbury eye evaluation. Invest. Ophthalmol. Vis. Sci. 48, 4445-4450.

Friedman, D.S., Freeman, E., Munoz, B., Jampel, H.D., West, S.K., 2007. Glaucoma and mobility performance: the salisbury eye evaluation project. Ophthalmology 114, 2232-2237.

Galna, B., Peters, A., Murphy, A.T., Morris, M.E., 2009. Obstacle crossing deficits in older adults: a systematic review. Gait Posture 30, 270-275.

Garden, S.E., Phillips, L.H., MacPherson, S.E., 2001. Midlife aging, open-ended planning: and laboratory measures of executive function. Neuropsychology 15 472-482.

Gatts, S.K., Woollacott, M.H., 2006. Neural mechanisms underlying balance improvement with short term Tai Chi training. Aging Clin. Exp. Res. 18, 7-19.

Gauchard, G.C., Jeandel, C., Perrin, P.P., 2001. Physical and sporting activities improve vestibular afferent usage and balance in elderly human subjects. Gerontology 47, 263-270.

Gérin-Lajoie, M., Richards, C.L., McFadyen, B.J., 2006. The circumvention of obstacles during walking in different environmental contexts: a comparison between older and younger adults. Gait Posture 24, 364-369.

Giné-Garriga, M., Guerra, M., Pagès, E., Manini, T.M., Jiménez Ro Unnithan, V.B., 2010. The effect of functional circuit training on physical frailty in frail older adults: a randomized controlled trial. J. Aging Phys. Act. 18, 401-424.

Goodman, J., Brewster, S.A., Gray, P., 2005. How can we best use landmarks to support older people in navigation? Behav. Inf. Technol. 24, 3-20.

Gorrie, C.A., Brown, J., Waite, P.M.E., 2008. Crash characteristics of older pedestrian fatalities: dementia pathology may be related to 'at risk' traffic situations. Accid. Anal. Prev. 40, 912-919.

Granacher, U., Zahner, L., Gollhofer, A., 2008. Strength, power, and postural control in seniors: considerations for functional adaptations and for fall prevention. Eur. J. Sport Sci. 8, 325-340.

Gras, D., Daniel, M.-P., Labiale, G., Piolino, P., Gyselinck, V., 2012. Effet du vieillissement sur la mémorisation d'itinéraires réels: l'importance de la mémoire de travail et de la mémoire épisodique. Gériatr. Psychol. NeuroPsychiatr. Vieil. 10, 463-470.

Grue, E.V., Ranhoff, A.H., Noro, A., Finne-Soveri, H., Jensdóttir, A.B., Ljunggren, G., Bucht, G., Björnson, L.J., Jonsén, E., Schroll, M., Jónsson, P.V., 2009. Vision and hearing impairments and their associations with falling and loss of instrumental activities in daily living in acute hospitalized older persons in five Nordic hospitals. Scand. J. Caring Sci. 23, 635-643.

Guccione, A.A., Felson, D.T., Anderson, J.J., 1990. Defining arthritis and measuring functional status in elders: methodological issues in the study of disease and physical disability. Am. J. Public Health 80, 945-949.

Halliday, S.E., Winter, D.A., Frank, J.S., Patla, A.E., Prince, F., 1998. The initiation of gait in young, elderly: and Parkinson's disease subjects. Gait Posture 8, 8-14.

Hanlon, J.T., Landerman, L.R., Fillenbaum, G.G., Studenski, S., 2002. Falls in African American and white community-dwelling elderly residents. J. Gerontol. Ser. A Biol. Sci. Med. Sci. 57, 473-478.

Hamel, K.A., Cavanagh, P.R., 2004. Stair performance in people aged 75 and older. J Am. Geriatr. Soc. 52, 563-567. 
Harley, C., Wilkie, R.M., Wann, J.P., 2009. Stepping over obstacles: Attention demands and aging. Gait Posture 29, 428-432.

Harris, M.A., Wolbers, T., 2014. How age-related strategy switching deficits affect wayfinding in complex environments. Neurobiol. Aging 35, 1095-1102, http:| dx.doi.org/10.1016/j.neurobiolaging.2013.10.086.

Harris, S.T., 2002. Osteoporosis: hard facts about bones. Johns Hopkins Adv. Stud. Med. 2, 546-550.

Harruff, R.C., Avery, A., Alter-Pandya, A.S., 1998. Analysis of circumstances and injuries in 217 pedestrian traffic fatalities. Accid. Anal. Prev. 30, 11-20.

Harwood, R.H., 2001. Visual problems and falls. Age Ageing 30, 13-18.

Hasher, L., Zacks, R.T., 1988. Working memory, comprehension, and aging: review and a new view. In: Bower, G.H. (Ed.), The Psychology of Learning and Motivation, vol. 22. Academic Press, New York, NY, pp. 193-225.

Hawkes, T.D., Siu, K.-C., Silsupadol, P., Woollacott, M.H., 2012. Why does older adults' balance become less stable when walking and performing a secondary task? Examination of attentional switching abilities. Gait Posture 35, 159-164

Haymes, S.A., Leblanc, R.P., Nicolela, M.T., Chiasson, L.A., Chauhan, B.C., 2007. Risk of falls and motor vehicle collisions in glaucoma. Invest. Ophthalmol. Vis. Sci. $48,1149-1155$

Head, D., Isom, M.1, 2010. Age effects on wayfinding and route learning skills. Behav. Brain Res. 209, 49-58.

Himes, C.L., Reynolds, S.L., 2012. Effect of obesity on falls, injury, and disability. J. Am. Geriatr. Soc. 60, 124-129.

Hochberg, M.C., Kasper, J., Williamson, J., Skinner, A., Fried, L.P., 1995. The contribution of osteoarthritis to disability: preliminary data from the Women's Health and Aging Study. J. Rheumatol. 43 (Suppl), 16-18.

Holland, C., Hill, R., 2010. Gender differences in factors predicting unsafe crossing decisions in adult pedestrians across the lifespan: a simulation study. Accid. Anal. Prev. 42, 1097-1106.

Holland, C.A., Rabbitt, P.M., 1992. People's awareness of their age-related sensory and cognitive deficits and the implications for road safety. Appl. Cogn. Psycho 6, 217-231.

Hollman, J.H., Kovash, F.M., Kubik, J.J., Linbo, R.A., 2007. Age-related differences in spatiotemporal markers of gait stability during dual task walking. Gait Posture 26, 113-119.

Holtzer, R., Friedman, R., Lipton, R.B., Katz, M., Xiaonan, X.U.E., Verghese, J., 2007. The relationship between specific cognitive functions and falls in aging. Neuropsychology 21, 540-548.

Hort, J., Laczó, J., Vyhnálek, M., Bojar, M., Bures, J., Vlcek, K., 2007. Spatia navigation deficit in amnestic mild cognitive impairment. Proc. Natl. Acad. Sci. U. S. A. 104, 4042-4047.

Hoxie, R.E., Rubenstein, L.Z., 1994. Are older pedestrians allowed enough time to cross intersections safely? J. Am. Geriatr. Soc. 42, 241-244.

Huguenin-Richard, F. (2012). La marche à pied pour les seniors, un mode de déplacement " durable "? In DEUFRAKO, séminaire franco-allemand sur l'impact du vieillissement de la population sur les transports terrestres, Strasbourg, $30 \mathrm{mai}$

Huitema, R.B., Brouwer, W.H., Mulder, T., Dekker, R., Hof, A.L., Postema, K., 2005 Effect of ageing on the ability to adapt to a visual distortion during walking. Gait Posture 21, 440-446.

Hunt, M., Harper, D.N., Lie, C., 2011. Mind the gap: training road users to use speed and distance when making gap-acceptance decisions. Accid. Anal. Prev. 43, 2015-2023.

Husband, P.A. 2010. A literature review of older driver training interventions: implications for the delivery programmes by Devon County Council and Devon Road Casualty Reduction Partnership. Devon County Council.

I'DGO (2010). Tactile paving design, siting and laying: Inclusive Design for Getting Outdoors.

ITF, 2012. Pedestrian Safety, Urban Space and Health. OECD Publishing, http://dx. doi.org/10.1787/9789282103654-en.

Ivers, R.Q. Cumming, R.G., Mitchell, P., Attebo, K., 1998. Visual impairment and falls in older adults: the Blue Mountains eye study. J. Am. Geriatr. Soc. 46, 58-64

Jermakian, J.S., 2011. Crash avoidance potential of four passenger vehicle technologies. Accid. Anal. Prev. 43, 732-740.

Katzman, W.B., Vittinghoff, E., Ensrud, K., Black, D.M., Kado, D.M., 2011. Increasing kyphosis predicts worsening mobility in older community-dwelling women: a prospective cohort study. J. Am. Geriatr. Soc. 59, 96-100.

Keall, M.D., 1995. Pedestrian exposure to risk of road accident in New Zealand. Accid. Anal. Prev. 27, 729-740.

Kirasic, K.C., 1991. Spatial cognition and behavior in young and elderly adults: mplications for learning new environments. Psychol. Aging 6, 10-18.

Klencklen, G., Després, O., Dufour, A., 2012. What do we know about aging and spatial cognition? Reviews and perspectives. Ageing Res. Rev. 11, 123-135.

Kliegel, M., Martin, M., McDaniel, M.A., Phillips, L.H., 2007. Adult age differences in errand planning: the role of task familiarity and cognitive resources. Exp. Aging Res. 33, 145-161

Knoblauch, R.L., Pietrucha, M.T., Nitzburg, M., et al., 1996. Field studies of pedestrian walking speed and start-up time. Transp. Res. Board 1538, 27-38.

Koepsell, T., McCloskey, L., Wolf, M., Moudon, A.V., Buchner, D., Kraus, J., Patterson, M., 2002. Crosswalk markings and the risk of pedestrian-motor vehicle collisions in older pedestrians. JAMA 288, 2136-2143.

Korner-Bitensky, N., Kua, A., von Zweck, C., Van Benthem, K., 2009. Older driver retraining: an updated systematic review of evidence of effectiveness. J. Saf. Res. 40, 105-111.

Kramer, A.F., Erickson, K.I., 2007. Effects of physical activity on cognition, well-being, and brain: human interventions. Alzheimer's Demen. 32, S45-S51.
Laessoe, U., Hoeck, H.C., Simonsen, O., Voigt, M., 2008. Residual attentional capacity amongst young and elderly during dual and triple task walking. Hum. Mov. Sci. 27, 496-512

Landi, F., Liperoti, R., Russo, A., Giovannini, S., Tosato, M., Capoluongo, E., Bernabei, R., Onder, G., 2012. Sarcopenia as a risk factor for falls in elderly individuals: results from the il SIRENTE study. Clin. Nutr. 31, 652-658.

Lee, H.J., Chou, L.S., 2007. Balance control during stair negotiation in older adults. J. Biomech. 40, 2530-2536.

Legters, K., 2002. Fear of falling. Phys. Ther. 82, 264-272.

Li, Y., Hsu, J.A., Fernie, G., 2013. Aging and the use of pedestrian facilities in winter-the need for improved design and better technology. J. Urban Health 90 (4), 602-617, http://dx.doi.org/10.1007/s11524-012-9779-2.

Lindenberger, U., Marsiske, M., Baltes, P.B., 2000. Memorizing while walking: increase in dual-task costs from young adulthood to old age. Psychol. Aging 15, 417-436.

Lipovac, K., Vujanic, M., Maric, B., Nesic, M., 2013. Pedestrian behavior at signalized pedestrian crossings. J. Transp. Eng. 139, 165-172.

Lips, P., Van Schoor, N.M., 2005. Quality of life in patients with osteoporosis Osteoporos. Int. 16, 447-455.

Liu, J.Y., 2015. Fear of falling in robust community-dwelling older people: results of a cross-sectional study. J. Clin. Nurs. 24, 393-405.

Liu, Y., Chan, J.S.Y., Yan, J.H., 2014. Neuropsychological mechanisms of falls in older adults. Front. Aging Neurosci. 6, 1-8.

Liu, L., Gauthier, L., Gauthier, S., 1991. Spatial disorientation in persons with early senile dementia of the Alzheimer type. Am. J. Occup. Ther. 45, 67-74.

Lobjois, R., Cavallo, V., 2007. Age-related differences in street-crossing decisions: The effects of vehicle speed and time constraints on gap selection in an estimation task. Accid. Anal. Prev. 39, 934-943.

Lobjois, R., Cavallo, V., 2009. The effects of aging on street-crossing behavior: from estimation to actual crossing. Accid. Anal. Prev. 41, 259-267.

Lopez, D., McCaul, K.A., Hankey, G.J., Norman, P.E., Almeida, O.P., Dobson, A.J., Byles, J.E., Yeap, B.B., Flicker, L., 2011. Falls, injuries from falls: health related quality of life and mortality in older adults with vision and hearing impairment-is there a gender difference. Maturitas 69, 359-364.

Lord, S.R., Clark, R.D., Webster, I.W., 1991. Physiological factors associated with falls in an elderly population. J. Am. Geriatr. Soc. 39, 1194-1200.

Lord, S., Luxembourg, N., 2006. The mobility of elderly residents living in suburban territories: mobility experiences in Canada and France. J. Hous. Elder. 20, 103-121.

Lord, S.R., Sherrington, C., Menz, H.B., 2001. Falls in Older People: Risk Factors and Strategies for Prevention. Cambridge University Press, Cambridge.

Lundin-Olsson, L., Nyberg, L., Gustafson, Y., 1997. Stops walking when talking as a predictor of falls in elderly people. Lancet 349, 617.

Maillot, P., Perrot, A., Hartley, A., 2012. Effects of interactive physical-activity videogame training on cognitive function in older adults. Psychol. Aging 27 589-600.

Malatesta, D., Simar, D., Saad, H.B., Préfaut, C., Caillaud, C., 2010. Effect of an overground walking training on gait performance in healthy $65-$ to 80-year-olds. Exp. Gerontol. 45, 427-434.

Mammarella, N., Fairfield, B., De Beni, R., Cornoldi, C., 2009. Aging and intrusion errors in an active visuo-spatial working memory task. Aging Clin. Exp. Res. 21, 282-291.

Marigold, D.S., Patla, A.E., 2008. Age-related changes in gait for multi-surface terrain. Gait Posture 27, 689-696.

Marottoli, R.A., Richardson, E.D., 1998. Confidence in, and self-rating of, driving ability among older drivers. Accid. Anal. Prev. 30, 331-336.

May, A.J., Ross, T., Bayer, S.H., Tarkiainen, M.J., 2003. Pedestrian navigation aids: Information requirements and design implications. Pers. Ubiquitous Comput. 7, 331-338.

McCarty, C.A., Fu, C.L., Taylor, H.R., 2002. Predictors of falls in the Melbourne Visual Impairment Project. Aust. N. Z. J. Public Health 26, 116-119.

McComas, J., MacKay, M., Pivik, J., 2002. Effectiveness of virtual reality for teaching pedestrian safety. Cyberpsychol. Behav. 5, 185-190.

McMurdo, M.E.T., Gaskell, A., 1991. Dark adaptation and falls in the elderly. Gerontology 37, 221-224

McPhillips, J.B., Pellettera, K.M., Barrett-Connor, E., Wingard, D.L., Criqui, M.H., 1989. Exercise patterns in a population of older adults. Am. J. Prev. Med. 5, $65-72$

Meinhart-Shibata, P., Kramer, M., Ashton-Miller, J.A., Persad, C., 2005. Kinematic analyses of the 180 degrees standing turn: effects of age on strategies adopted by healthy young and older women. Gait Posture 22, 119-125.

Miller, S.L., Wolfe, R.R., 2008. The danger of weight loss in the elderly. J. Nutr. Health Aging 12, 487-491.

Moffat, S.D., 2009. Aging and spatial navigation: what do we know and where do we go? Neuropsychol. Rev. 19, 478-489.

Mollenkopf, H., Marcellini, F., Ruoppila, I., Flaschenträger, P., Gagliardi, C. Spazzafumo, L., 1997. Outdoor mobility and social relationships of elderly people. Arch. Gerontol. Geriatr. 24, 295-310.

Muir, B.C., Rietdyk, S., Haddad, J.M., 2014. Gait initiation: the first four steps in adults aged $20-25$ years, 65-79 years and $80-91$ years. Gait Posture 39, 490-494.

Nagamatsu, L.S., Voss, M., Neider, M.B., Gaspar, J.G., Handy, T.C., Kramer, A.F., Liu-Ambrose, T.Y., 2011. Increased cognitive load leads to impaired mobility decisions in seniors at risk for falls. Psychol, Aging 26, 253-259. 
Naumann, R.B., Dellinger, A.M., Haileyesus, T., Ryan, G.W., 2011. Older adult pedestrian injuries in the United States: causes and contributing circumstances. Int. J. Inj. Control Saf. Promot. 18, 65-73.

Naveteur, J., Delzenne, J., Sockeel, P., Watelain, E., Dupuy, M.A., 2013. Crosswalk time estimation and time perception: an experimental study among older female pedestrians. Accid. Anal. Prev. 60, 42-49.

Neider, M.B., Gaspar, J.G., McCarley, J.S., Crowell, J.A., Kaczmarski, H., Kramer, A.F., 2011. Walking and talking: dual-task effects on street crossing behavior in older adults. Psychol. Aging 26, 260-268.

ONISR, 2006. Grands thèmes de la sécurité routière en France. La Documentation Française, Paris.

Owsley, C., McGwin Jr., G., 2004. Association between visual attention and mobility in older adults. J. Am. Geriatr. Soc. 52, 1901-1906.

Oxley, J., Fildes, B., Ihsen, E., Charlton, J., Day, R., 1997. Differences in traffic judgments between young and old adult pedestrians. Accid. Anal. Prev. 29, 839-847.

Oxley, J., Fildes, B., Ihsen, E., Day, R.H., Charlton, J.L., 1995. An Investigation of Road Crossing Behaviour of Older Pedestrians. Monash University Accident Research Center.

Oxley, J.A., Ihsen, E., Fildes, B.N., Charlton, J.L., Day, R.H., 2005. Crossing roads safely: an experimental study of age differences in gap selection by pedestrians. Accid. Anal. Prev. 37, 962-971.

Paquette, M.R., Vallis, L.A., 2010. Age-related kinematic changes in late visual-cueing during obstacle circumvention. Exp. Brain Res. 203, 563-574

Patel, M., Fransson, P.A., Karlberg, M., Malmstrom, E.M., Magnusson, M., 2010. Change of body movement coordination during cervical proprioceptive disturbances with increased age. Gerontology 56, 284-290.

Phillips, J., Walford, N., Hockey, A., Foreman, N., Lewis, M., 2013. Older people and outdoor environments: pedestrian anxiety and barriers in the use of familiar and unfamiliar spaces. Geoforum 47, 113-124.

Phillips, L.H., Kliegel, M., Martin, M., 2006. Age and planning tasks: the influence of ecological validity. Int. J. Aging Hum. Dev, 62, 175-184.

Pijnappels, M., Reeves, N.D., Maganaris, C.N., van Dieën, J.H., 2008. Tripping without falling; lower limb strength, a limitation for balance recovery and a target for training in the elderly. J. Electromyogr. Kinesiol. 18, 188-196.

Plummer-D’Amato, P., Altmann, L.J.P., Reilly, K., 2011. Dual-task effects of spontaneous speech and executive function on gait in aging: exaggerated effects in slow walkers. Gait Posture 33, 233-237

Prioli, A.C., Cardozo, A.S., Barbosa De Freitas, P.J.R., Barela, J.A., 2006. Task demand effects on postural control in older adults. Hum. Mov. Sci. 25, 435-446.

Quek, J., Pua, Y.-H., Clark, R.A., Bryant, A.L., 2013. Effects of thoracic kyphosis and forward head posture on cervical range of motion in older adults. Man. Ther. $18,65-71$

Rainville, C., Passini, R., Marchand, N., 2001. A multiple case study of wayfinding in dementia of the Alzheimer type: decision making. Aging Neuropsychol. Cogn. 8, 54-71.

Rodrigues, J., Pinto, M., Dommes, A., Cavallo, V., Vienne, F., 2012. Simulated traffic and auditory information: the impact on street crossing in young and old adults. In: Proceedings of the Driving Simulation Conference (DSC) Europe, September.

Roenker, D.L., Cissell, G.M., Ball, K.K., Wadley, V.G., Edwards, J.D., 2003. Speed-of-processing and driving simulator training result in improved driving performance. Hum. Factors 45, 218-233.

Romero-Ortuno, R., 2010. The regulation of pedestrian traffic lights in Spain: do older people have enough time to cross the road? Rev. Esp. Geriatr. Gerontol. 45, 199-202.

Romero-Ortuno, R., Cogan, L., Cunningham, C.U., Kenny, R.A., 2010. Do older pedestrians have enough time to cross roads in Dublin? A critique of the Traffic Management Guidelines based on clinical research findings. Age Ageing 39, 80-86.

Rosano, C., Studenski, S.A., Aizenstein, H.J., Boudreau, R.M., Longstreth, W.T., Newman, A.B., 2012. Slower gait: slower information processing and smaller prefrontal area in older adults. Age Ageing 41, 58-64.

Rosén, E., Sander, U., 2009. Pedestrian fatality risk as a function of car impact speed. Accid. Anal. Prev. 41, 536-542.

Rosenbaum, R.S., Winocur, G., Binns, M.A., Moscovitch, M., 2012. Remote spatial memory in aging: all is not lost. Front. Aging Neurosci. 4, 25.

Rosenbloom, T., Mandel, R., Rosner, Y., Eldror, E., 2015. Hazard perception test for pedestrians. Accid. Anal. Prev. 79, 160-169.

SafetyNet, 2009. Pedestrian and Cyclists. DG-TREN European Commission.

Sanders, C., Schmitter-Edgecombe, M., 2012. Identifying the nature of impairment in planning ability with normal aging. J. Clin. Exp. Neuropsychol. 34, 724-737.

Salonen, J., Johansson, R., Karjalainen, S., Vahlberg, T., Isoaho, R., 2011. Relationship between self-reported hearing and measured hearing impairment in an elderly population in Finland. Int. J. Audiol. 50, 297-302.

Salthouse, T.A., 1996. The processing-speed theory of adult age differences in cognition. Psychol. Rev. 103, 403-428.

Salthouse, T.A., Atkinson, T.M., Berish, D.E., 2003. Executive functioning as a potential mediator of age-related cognitive decline in normal adults. J. Exp. Psychol.: Gen. 132, 566-594.

Salthouse, T.A., Siedlecki, K.L., 2007. Efficiency of route selection as a function of adult age. Brain Cogn. 63, 279-286.

Salzman, B., 2010. Gait and balance disorders in older adults. Am. Fam. Physician $82,61-68$
Scheffer, A.C., Schuurmans, M.J., Van Dijk, N., Van der Hooft, T., de Rooij, S.E., 2008. Fear of falling: measurement strategy, prevalence: risk factors and consequences among older persons. Age and Ageing 37, 19-24.

Schellenbach, M., Lövdén, M., Verrel, J., Krüger, A., Lindenberger, U., 2010. Sensorimotor-cognitive couplings in the context of assistive spatial navigation for older adults. Geropsych 23, 69-77.

Schepens, S.L., Panzer, V., Goldberg, A., 2011. Randomized controlled trial comparing tailoring methods of multimedia-based fall prevention education for community-dwelling older adults. Am. J. Occup. Ther. 65, 702-709.

Sekuler, R., Hutman, L.P., Owsley, C.J., et al., 1980. Human aging and spatial vision. Science 209, 1255-1256.

Shallice, T., Burgess, P.W., 1991. Deficits in strategy application following frontal lobe damage in man. Brain 114, 727-741.

Sheridan, P.L., Hausdorff, J.M., 2007. The role of higher-level cognitive function in gait: executive dysfunction contributes to fall risk in Alzheimer's disease. Demen. Geriatr. Cogn. Disord. 24, 125-137.

Shinar, D., Schieber, F., 1991. Visual requirements for safety and mobility of olde drivers. Hum. Factors: J. Hum. Factors Ergon. Soci. 33, 507-519.

Shkuratova, N., Morris, M.E., Huxham, F., 2004. Effects of age on balance control during walking. Arch. Phys. Med. Rehabil. 85, 582-588.

Shumway-Cook, A., Woollacott, M., Kerns, K.A., Baldwin, M., 1997. The effects of two types of cognitive tasks on postural stability in older adults with and without a history of falls. J. Gerontol.: Med. Sci. 52A, M232-M240.

Sinaki, M., Brey, R.H., Hughes, C.A., Larson, D.R., Kaufman, K.R., 2005. Balance disorder and increased risk of falls in osteoporosis and kyphosis: significance of kyphotic posture and muscle strength. Osteoporos. Int. 16, 1004-1010.

Sjölinder, M., Höök, K., Nilsson, L.-G., Andersson, G., 2005. Age differences and the acquisition of spatial knowledge in a three-dimensional environment: evaluating the use of an overview map as a navigation aid. Int. J. Hum.-Comput. Stud. 63, 537-564.

Smith, S.L., Bennett, L.W., Wilson, R.H., 2008. Prevalence and characteristics of dua sensory impairment (hearing and vision) in a veteran population. J. Rehabil. Res. Dev. 45, 597-609.

Snowden, R.J., Kavanagh, E., 2006. Motion perception in the ageing visual system: minimum motion, motion coherence, and speed discrimination thresholds. Perception 35 (1), 9-24

Sparrow, W.A., Bradshaw, E.J., Lamoureux, E., Tirosh, O., 2002. Ageing effects on the attention demands of walking. Hum. Mov. Sci. 21, 961-972.

Spirduso, W.W., Francis, K.L., MacRae, P.G., 2005. Physical Dimensions of Aging (2nd). Human Kinetics Publishers, Champaign, Ill., United States.

Ståhl, A., Carlsson, G., Hovbrandt, P., Iwarsson, S., et al., 2008. 'Let's go for a walk!'; Identification and prioritisation of accessibility and safety measures involving elderly people in a residential area. Eur. J. Ageing 5, 265-273.

Stenholm, S., Sainio, P., Rantanen, T., Alanen, E., Koskinen, S., 2007. Effect of co-morbidity on the association of high body mass index with walking limitation among men and women aged 55 years and older. Aging Clin. Exp. Res. 19, 277-283.

Svanström, L., 1974. Falls on stairs: an epidemiological accident study. Scand. J. Public Health 2, 113-120.

Szabo, S.M., Janssen, P.A., Khan, K., Potter, M.J., Lord, S.R., 2008. Older women with age-related macular degeneration have a greater risk of falls: a physiological profile assessment study. J. Am. Geriatr. Soc. 56, 800-807.

Taillade, M., Sauzéon, H., Dejos, M., Pala, P.A., Larrue, F., Wallet, G., Gross, C., N'Kaoua, B., 2013. Executive and memory correlates of age-related differences in wayfinding performances using a virtual reality application. Aging Neuropsychol. Cogn. 20, 298-319.

Taillade, M., N'Kaoua, B., Arvind Pala Sauzéon, H., 2014. Cognition spatiale et vieillissement: les nouveaux éclairages offerts par les études utilisant la réalité virtuelle. Revue de Neuropsychologie, Neurosciences cognitives et cliniques 6 , 36-41.

Thomson, J.A., Tolmie, A.K., Foot, H.C., Sarvary, P., Whelan, K.M., Morrison, S., 2005 Influence of virtual reality training on the roadside crossing judgments of child pedestrians. J. Exp. Psychol.-Appl. 11, 175-186.

Thompson, M., Medley, A., 1995. Performance of community dwelling elderly on the timed up and go test. Phys. Occup. Ther. Geriatr. 13, 17-30.

Tinetti, M.E., Powell, L., 1993. Fear of falling and low self-efficacy: a cause of dependence in elderly persons. J. Gerontol. 48, 35-38.

Tinetti, M.E., Speechley, M., Ginter, S.F., 1988. Risk factors for falls among elderly persons living in the community. N. Engl. J. Med. 319, 1701-1707.

Tirosh, O., Sparrow, W.A., 2004. Gait termination in young and older adults: effects of stopping stimulus probability and stimulus delay. Gait Posture 19, 243-251.

Uemura, K., Yamada, M., Nagai, K., Tanaka, B., Mori, S., Ichihashi, N., 2012. Fear of falling is associated with prolonged anticipatory postural adjustment during gait initiation under dual-task conditions in older adults. Gait Posture 35, 282-286.

Underwood, G., Chapman, P., Bowden, K., Crundall, D., 2002. Visual search while driving: skill and awareness during inspection of the scene. Transp. Res. Part F:Traffic Psychol. Behav. 5, 87-97.

Van Houten, R., Malenfant, L., Rolider, A., 1985. Increasing driver yielding and pedestrian signaling with prompting, feedback: and enforcement. J. Appl. Behav. Anal. 18, 103-110.

Viljanen, A., Kaprio, J., Pyykkö, I., Sorri, M., Koskenvuo, M., Taina, R., 2009. Hearing acuity as a predictor of walking difficulties in older women. J. Am. Geriatr. Soc. 57, 2282-2286.

Visser, M., 2011. Obesity, sarcopenia and their functional consequences in old age. Proc. Nutr. Soc. 70, 114-118. 
Ward, H., Cave, B.L., Morrison, A., Allsop, R., Evans, A., 1994. Pedestrian Activity and Accident Risk. AA Foundation for Road Safety Research, Basingstoke.

Welmerink, D.B., Longstreth Jr., W.T., Lyles, M.F., Fitzpatrick, A.L., 2010. Cognition and the risk of hospitalization for serious falls in the elderly: results from the Cardiovascular Health Study. J. Gerontol. Ser. A Biol. Sci. Med. Sci. 65 1242-1249.

Wennberg, H., Ståhl, A., Hydén, C., 2009. Older pedestrians' perceptions of the outdoor environment in a year-round perspective. Eur. J. Ageing 6, 277-290.

Wilkniss, S.M., Jones, M.G., Korol, D.L., Gold, P.E., Manning, C.A., 1997. Age-related differences in an ecologically based study of route learning. Psychol. Aging 12 372-375.

Williamson, J.D., Fried, L.P., 1996. Characterization of older adults who attribute functional decrements to old age. J. Am. Geriatr. Soc. 44

Wilson, B.A., Alderman, N., Burgess, P.W., Emslie, H., Evans, J.J., 1996. The Behavioural Assessment of the Dysexecutive Syndrome. Thames Valley Company, Bury St Edmunds.

Winter, D.A., Patla, A.E., Frank, J.S., Walt, S.E., 1990. Biomechanical walking pattern changes in the fit and healthy elderly. Phys. Ther. 70, 340-347.
Woollacott, M.H., Tang, P.F., 1997. Balance control during walking in the older adult: research and its implications. Phys. Ther. 6, 646-660.

WHO, 2007. Global Age-friendly Cities: a Guide. World Health Organization, Geneva, Switzerland, Library Cataloguing-In-Publication Data.

Yamamoto, N., DeGirolama, G.J., 2012. Differential effects of aging on spatial learning through exploratory navigation and map reading. Front. Aging Neurosci. 4, 14.

Yen, I.H., Anderson, L.A., 2012. Built environment and mobility of older adults: important policy and practice efforts. J. Am. Geriatr. Soc. 60, 951-956.

Zakzanis, K.K., Quintin, G., Graham, S.J., Mraz, R., 2009. Age and dementia related differences in spatial navigation within an immersive virtual environment. Med. Sci. Monitor: Int. Med. J. Exp. Clin. Res. 15, 140-150.

Zijlstra, G.A.R., van Haastregt, J.C.M., van Rossum, E., van Eijk, J.T.M., Yardley, L., Kempen, G.I.J., 2007. Interventions to reduce fear of falling in community-living older people: a systematic review. J. Am. Geriatr. Soc. 55, 603-615.

Zivotofsky, A.Z., Eldror, E., Mandel, R., Rosenbloom, T., 2012. Misjudging their own steps: why elderly people have trouble crossing the road. Hum. Factors 54 (60), 0-607. 